\title{
Nesnelerin İnternetinde Kullanılan Kablosuz Algılayıcı Cihazlar için Bilgi Merkezli Ăg Mimarisinin Uygulanabilirliği Araştırması
}

\author{
Çiğdem Eriş ${ }^{1 *}$, Pınar Sarısaray Bölük ${ }^{2}$ \\ 1* Bahçeşehir Üniversitesi, Mühendislik Fakültesi, Bilgisayar Mühendisliği Bölümü, İstanbul, Türkiye (ORCID: 0000-0002-2799-9251), cigdem.eris@eng.bau.edu.tr \\ ${ }^{2}$ Bahçeşehir Üniversitesi, Mühendislik Fakültesi, Yazılım Mühendisliği Bölümü, İstanbul, Türkiye (ORCID: 0000-0001-8274-8423), pinar.sarisaray@eng.bau.edu.tr
}

(İlk Geliş Tarihi 18 Mayıs 2020 ve Kabul Tarihi 26 Aralık 2020)

(DOI: 10.31590/ejosat.739400)

ATIF/REFERENCE: Eriş, Ç. \&Bölük, P. (2021). A Survey of Applicability of Information Centric Networking on Wireless Sensor Devices used in Internet of Things. Avrupa Bilim ve Teknoloji Dergisi, (21), 160-171.

\section{$\ddot{O} z$}

Bilgi merkezli ağlar, (ICN - Information Centric Networks), istemci-sunucu arasında uçtan uca iletişimin kurulmadığı, kullanıcıların içerik talebini farklı sunuculardan karşılayabildiği bir ağ mimarisidir. Bu mimari, talep edilen verinin kaynak haricinde ağdaki ara düğümlerin önbelleğine kaydedilmesi ile, veriye hızlı ve kolay erişim sağlamaktadır. Ayrıca bu şekilde ağda yayılan veri, içeriğini sertifikalandırması sayesinde güvenli olarak temin edilebilmektedir. Bu nedenle ICN mimarisi, sadece geleneksel İnternet uygulamaları için değil, bunun ötesinde Nesnelerin İnternet'i (IoT) uygulamalarında da cazip hale gelmektedir. Nesnelerin İnternet’i kullanıcı ve çevresinin web uygulamaları ve servisleri ile bütünleşmesini amaçlamaktadır. Bu amaç doğrultusunda kablosuz algılayıcılar, internete bağlı cihazlara duyusal bir uzantı sağlayarak "nesne" olarak tanımlanabilmekte, çok sayıda uygulama ve servis bu nesnelerin çevreleri ile ilgili ürettiği içeriklerden faydalanabilmektedir. Dolayısıyla IoT uygulamalarının çoğunluğunda içerik, üretildiği konum veya cihaza kıyasla daha ön plana çıkmaktadır. Bu kapsamda IoT kavramının en önemli bileşeni olan, farklı donanım ve haberleşme teknolojilerine sahip düşük maliyetli kablosuz algılayıcı ağların, mevcut internet altyapısına dahil edilmeleri ve birbirleriyle ürettikleri içerikleri paylaşması gerekmektedir. Ancak kablosuz algılayıcı cihazların işlemci gücü, bellek kapasitesi ve enerji kaynakları sınırlıdır. Bu cihazların, mevcut haberleşme standartlarını kullanarak internete entegre olmaları maliyetli olabilmektedir. Kaynakları kısıtlı olan kablosuz algılayıcı cihazların, küresel bir iletişim ağının parçası haline gelmesi uygulama ve ağ katmanında çözülmesi gereken pek çok yeni problemi ortaya çıkarmaktadır. Bu doğrultuda kablosuz algılayıcı cihazlar yer aldıkları uygulamanın gereksinimleri ve kullanım alanlarına bağlı olarak, bağlantı merkezli (uçtan uca) veya bilgi merkezli ağ mimarilerinden faydalanabileceklerdir. Bu çalışmada, bilgi merkezli ağ mimarisinin kablosuz algılayıcı cihazlar için uygulanabilirliği, sunacağı avantajlar ve mevcut eksikleri literatürde yapılan çalışmalar göz önüne alınarak irdelenmiştir.

\section{A Survey of Applicability of Information Centric Networking on Wireless Sensor Devices used in Internet of Things}

\begin{abstract}
Information-centric Networks (ICN) is a new communication paradigm in which end-to-end connection establishment is not necessary between client-server and users can retrieve contents from different sources. In this paradigm, data is disseminated from the caches of intermediate nodes along the communication path other than the source, thus, enabling fast and efficient content delivery. Furthermore, by certificating the content itself rather than the transmission medium, ICN ensures content security. These features of ICN is attracting not only for traditional Internet applications, but also for Internet of Things (IoT) environments. The Internet of Things aims to integrate the user and its surroundings with web applications and services by exploiting wireless sensors attached to "things" which is connected to Internet and provides a sensory extension to the physical world. Thus, many applications and services can gather information about the surroundings of "things". Hence, in the majority of IoT applications, information is more essential than the location of which it is retrieved from. In this context, low-cost wireless sensor networks with different hardware and
\end{abstract}

*Sorumlu Yazar: cigdem.eris@eng.bau.edu.tr 
communication technologies, are the most important components of IoT concept, and need to be incorporated with existing internet infrastructure to share their contents with each other. However, wireless sensor network devices have limited resources in terms of processing, memory capabilities and energy resources. Therefore, integrating these constrained devices into global communication network arises many new problems that need to be solved in the network layer and complex adaptations in the application layer. However, they can utilize from both connection and information-oriented architectures depending on the application areas and requirements. In this study, applicability of information-centric architectures is examined for wireless sensor devices that used in the IoT applications. Advantages and disadvantages are studied by considering the existing surveys and studies in literature.

Keywords: Information Centric Networks, Internet of Things, Wireless Sensor Networks.

\section{Giriş}

Nesnelerin interneti (IoT), her bir cihazı İnternet'e bağlamayı amaçlamaktadır, böylece bu cihazlara herhangi bir zamanda, herhangi bir yerde ve herhangi bir yoldan (yani herhangi bir ağdan) erişilebilmektedir (Nour, Sharif, Li, BiswasMoungla, Guizani\&Wang 2019). Bu kavram, İnternet'in kablosuz algılayıcı cihazlar aracılığıyla fiziksel dünyaya bağlandığı yeni bir iletişim sistemi olarak tanımlanmıştır. Bunun sonucunda, gündelik cihazlar, bulundukları ortam hakkında bilgi toplayan ve ürettiği bilgiyi, küresel bir uygulama ekosistemine sağlayan bir ağ bileşeni haline gelmiştir. Kablosuz teknolojiye sahip her nesne çok sayıda uygulama ve kullanıcıya veri sağlama potansiyelini taşımaktadır. Ancak bu potansiyelin gerçekleştirilebilmesi için farklı haberleşme standartlarına ve donanım kısıtlarına sahip kablosuz cihazların birbirleri ve mevcut internet protokolleri ile uyumlu çalışmaları gerekmektedir (Castellani, Bui, Casari, Rossi, Shelby, \&Zorzi, 2010).

Günümüzde akıllı ev, sağlık, tarım ve endüstri uygulamalarında kullanılan kablosuz algılayıcı ağlar, çoğunlukla belirli sayıda kullanıcıya bilgi sağlamak amacı ile yerel alan ağlarında çalışmaktadır (Waltari\&Kangasharju, 2016). Geleneksel kablolu ağlar için tasarlanmış TCP/IP yığını üzerinde çalışan uygulama protokollerinin, donanım kaynakları kısıtlı cihazlarda doğrudan kullanılamaması sebebi ile bu ağlar, kullanıcı ve algılayıcı cihazlar arasındaki bir ağ ara geçidi aracılığı ile internete bağlanmaktadır (Dunkels, Alonso, \&Voigt, 2003), (Stann\&Heidemann, 2003). Bu durum, her yeni uygulamanın, kablosuz algılayıcı ağ üzerinde tanımlı mevcut protokollerde değişiklik yapılmasını gerektirdiğinden, zaman alıcı ve zahmetli olmaktadır (Sheng, Yang, Yu, Vasilakos, Mccann\&Leung, 2013). Bu nedenle kablosuz algılayıcı ağlar internet altyapısına doğrudan entegre edilememektedir (IEEE St. 1451.5-2007). Kablosuz algılayıcı ağlarda, TCP/IP yığın modelinde kullanılan geleneksel uygulama protokollerinin yerine cihazların kısıtlarını dikkate alarak geliştirilen CoAP (Bormann, Castellani\&Shelby, 2012), MQTT (Hunkeler, Truong\& Stanford-Clark, 2008), STMP (Aschenbruck\&Fuchs, 2011), vb. uygulama protokolleri önerilmiştir. Bu uygulama protokolleri HTTP protokolünün basitleştirilmiş versiyonları olarak IP protokolü üzerinde çalışmaktadır ve her bir cihazın IP adresine sahip olmasını gerektirmektedir. 2023 yılında internete bağlı cihaz sayısının 29 Milyarın üzerinde olacağı ve internet trafiğini IoT cihazlarının yöneteceği göz önünde bulundurulduğunda (Cisco, 2020) çok sayıda cihazın adreslenebilmesi ve oluşan trafiğin mevcut altyapı tarafindan desteklenebilmesi gibi ihtiyaçlar ortaya çıkmaktadır.

Bu kapsamda önerilen 6LoWPAN adaptasyon katmanı ile IPv6/6LoWPAN protokol yığını, kablosuz algılayıcı cihazların IPv6 adresi kullanarak dış IP ağlarına bağlanmasını sağlamıştır
(Shelby\&Bormann, 2009). Ancak IPv6 yönteminin uçtan uca iletişimi desteklemesi nedeniyle maalesef IoT cihazlarının sebep olduğu trafik dar boğazına karşı farklı çözüm önerileri gerekmektedir. $\mathrm{Bu}$ kapsamda uçtan uca yapılan iletişime alternatif olarak son yıllarda en dikkat çeken çözüm önerisi, bilgi merkezli ağ mimarisidir (ICN- Information Centric Networks) (Jacobson, Smetters, Thornton, Plass, Briggs\&Braynard, 2009). $\mathrm{Bu}$ mimari, hedef ve kaynak düğümler arasında adres temelli haberleşme yapmak yerine, içerik/veriye odaklanan bir ağ modeli önermektedir. ICN'de yer alan isimlendirme (naming), yönlendirme (routing), önbelleğe alma (caching) ve içerik güvenliğinin sağlanması (securing content) gibi yöntemler IoT uygulamaları için avantaj sağlamaktadır. Veri, bulunduğu adresten bağımsız olarak, verinin isimlendirilmesi ile temin edilmektedir. Buna ek olarak, verinin kaynağından bağımsız olarak aynı ağdaki kablosuz cihazların veriyi önbelleğe almaları yöntemi ile hızlı ve verimli içerik temini sağlanmaktadır (Castellani et al., 2010). Böylece bilgi merkezli yaklaşım, geleneksel internet mimarisinin gerektirdiği uçtan uca bağlantının kurulması ve sürdürülmesi zorunluluğunu ortadan kaldırarak, kablosuz algılayıcı ağların internete dahil edilmesi sürecinde güçlü bir aday olmuştur.

Donanım özellikleri ve ürettikleri veri bakımından birbirinden farklı çok sayıda cihazın birbiri ve internet protokolleri ile uyumlu çalışabilmesi, literatürde üzerinde sık çalışılan bir konu olmuştur. $\mathrm{Bu}$ makalede, bilgi merkezli yaklaşımın, IoT uygulamalarında kullanılan kablosuz algılayıcı cihazlarda uygulanabilirliği mevcut çalışmalar doğrultusunda araştırılmıştır. Bilgi merkezli ă̆ mimarisinin, haberleşme protokollerine getirmiş olduğu avantaj ve dezavantajları ile kısıtlı cihazlar tarafından kullanılabilirliği incelenmiştir. Makalenin kalan kısmı şu şekilde düzenlenmiştir. 2. Bölümde nesnelerin interneti kavramının tanımına, içerdiği teknolojilere ve uygulama alanlarına yer verilmiştir. 3. Bölümde nesnelerin interneti uygulamalarının uçtan uca çalışabilirliği için literatürdeki çalışmalar incelenmiştir. 4. Bölümde bilgi merkezli ağ mimarisinin tanımı ve kullanım senaryoları verilmiştir. 5. Bölümde bilgi merkezli ağ mimarisinin getirdiği avantajlar üzerinde durulmuştur. 6 . Bölümde bilgi merkezli ağ mimarisinin nesnelerin interneti cihazları üzerinde çalışabilirliği incelenmiş olup 7. Bölümde sonuç verilmiş ve bilgi merkezli ağ mimarisinin bu kapsamda ileriye dönük potansiyel araştırma alanları belirtilmiştir.

\section{Nesnelerin İnterneti}

IoT, ekosistemde yer alan tüm nesnelerin Internet'e bağlanmasına olanak veren bir sistemdir. Bu küçük nesneler kendi aralarında haberleşebilme yetilerinin yanında Internet'e direk veri yollayabilme veya Internet' den gelen veri ile komut alarak harekete geçme özelliklerine sahiptirler. Dolayısıyla IoT, farklı özellikleri olan nesnelerin veri toplama, kaynak paylaşımı, 
analiz ve yönetim gibi amaçlar için Internet' den ulaşılabilir olmasına olanak verir (Gubbi, Buyya, Marusic, \&Palaniswami, 2013), (Atzori, Iera, \&Morabito, 2010). Bunun sonucunda, ulaşım, sağlık, çevre, tarım, vb. çeşitli iş alanlarında kullanılan akıllı cihazlar, algılayıcı ve aktüatör özelliğine sahip olmalarının yanı sıra, birer akıllı internet bileşeni haline gelmişlerdir (Aydemir, 2019). IoT, bu cihazlardan toplanan verilerin, yapay zekâ, veri madenciliği gibi uygulama alanlarında kullanılan yöntemler ile bilgiye dönüşümünü ve bu bilginin çok sayıda uygulama veya kullanıcıya servis edilmesini amaçlamaktadır. Bununla beraber, farklı donanım/haberleşme kaynaklarına sahip kablosuz algılayıcıların büyük ölçekli uygulamalarda kullanılabilmesi için standartlaşma çalışmaları yapılmıştır (Sheng et al., 2013), (Atzori et al., 2010), (Tagami\&Arumaithurai, 2016), (Chen, 2017), (Lin, Yu, Zhang, Yang, Zhang\&Zhao, 2017).

Günümüzde algılayıcı cihazlardan elde edilen çeşitli ölçüm bilgilerini mevcut internet protokolleri ile kullanıcıya taşıan uygulamaların büyük bir kısmı, yerel alan ağlarında (LAN Local Area Networks) çalışmaktadır (Waltari et al., 2016). Nesnelerin interneti, uygulama alanlarına bağlı olarak algılayıcı düğümlerden elde edilen ölçüm bilgilerinin internet üzerinde çok sayıda kullanıcıya ve servise bilgi sağlamasını amaçlar. Bu doğrultuda, IoT uygulamaları ve hali hazırda kullanılmakta olan teknolojiler Şekil 1'de 5 ayrı katmanda incelenmiştir: Nesne/Cihaz Katman1, Bağlantı Katmanı, Yönetim Katman1, Veri İşleme ve Analiz Katmanı, Uygulama Katmanı. Bu mimari ile algılayııı düğümlerin internet üzerinden gerçek zamanlı veya periyodik olarak sağladıkları veri, birçok uygulama ve kullanıcı tarafindan kullanılabilecektir.

Şekil 1. Nesnelerin Interneti: İletişim Teknolojileri ve Uygulamalar

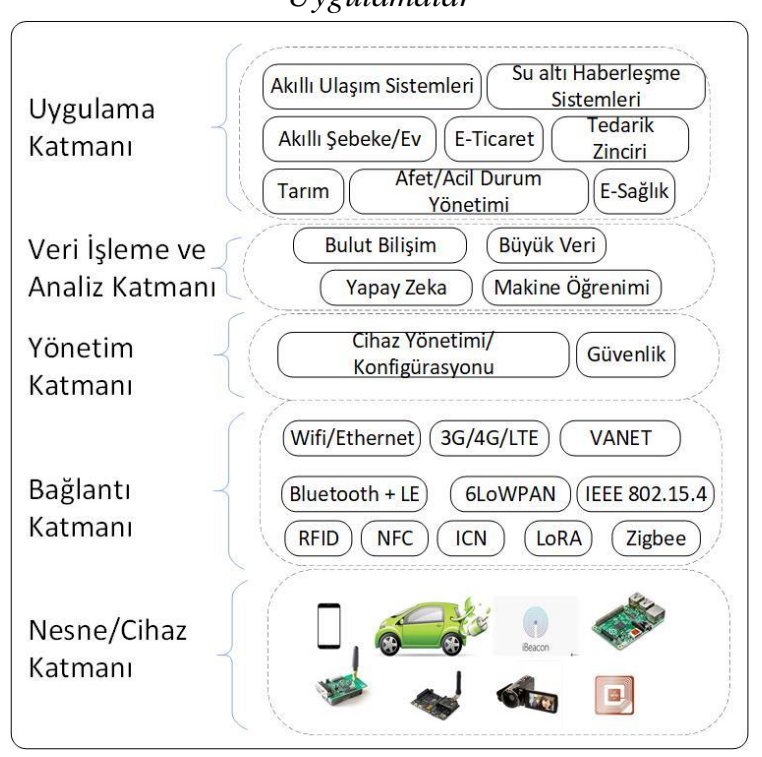

Şekil 1'de her bir katman bilginin üretim ve kullanım alanını temsil etmektedir. Nesne katmanında her cihaz bulunduğu ortam ile ilgili bilgi toplamaktadır. $\mathrm{Bu}$ katmandaki nesnelerin tanımlanması ve takibi RFID teknolojisi ile sağlanırken, yakınlık, duman, sıcaklık, 1şık vb. ölçülmesi gereken bilgiler diğer algılayıcı cihazlar ile tanımlanabilmektedir. Bağlantı katmanı farklı teknolojilere sahip cihazların isimlendirildiği ve üretilen ölçüm verilerinin (sıcaklık, sşık vb.) iletildiği katmandır. $\mathrm{Bu}$ katmanda her cihaz sahip olduğu haberleşme teknolojisi (Zigbee (IEEE 802.15.4), 6LoWPAN, NFC, Bluetooth vb.) ile ürettiği bilgiyi yönetim ve veri işleme üst katmanlarına taşımaktadır. Güvenlik, ortam erişim denetimi, cihazların kurulum ve konfigürasyonu yönetim katmanında yapılmaktadır. $\mathrm{Bu}$ katman kablosuz cihazların periyodik çalışma sürelerinin, keşif ve yapılandırma protokollerinin yerel ağ alanında ayarlandığı katmandır. Üretilen bilgi uygulama katmanında son kullanıcılar tarafindan kullanılabilmekte, aynı zamanda veri işleme ve analiz katmanında farklı uygulama alanlarına bilgi sağlamaktadır. Uygulama katmanında, cihazlardan elde edilen ve anlamlandırılmış bilgiler şüpheli olay tespiti, verimli enerji tüketimi, iş güvenliği vb. birçok uygulamada kullanılabilmektedir (Ersin \& Öz, 2020). Örneğin; akıllı ev ve akıllı şebeke uygulamalarında kullanılan algılayıcı düğümler tarafindan ölçülen elektrik tüketim bilgisi, elektrik şirketleri tarafından arz talep optimizasyonu yapılmasında kullanılabildiği gibi, tüketici tarafindan tasarruf ve tüketim planı yapılmasında da kullanılabilir.

Vücut alan algılayıcı düğümler ile nesnelerin interneti kapsamında ortaya çıkan bir diğer uygulama alanı akıllı sağlık sistemleridir. Vücut alan algılayıcı düğümlerden elde edilen fiziksel ölçüm bilgileri Bluetooth vb. bir iletişim teknolojisi yardımı ile akıllı telefon aracılığı ile gerçek zamanlı takip edilebilir veya bulut teknolojisi ile bu ölçümler doktorlar tarafindan kontrol edilebilir. Buna ek olarak yaşlı gözetim sistemleri örnek verilebilir. Hastanın uzaktan gerçek zamanlı gözetimi sağlanabilir ve algılayıcı düğümler yardımı ile kan değeri, kalp atışı gibi fiziksel ölçümleri takip edilebilir (Atzori et al., 2010). Yakin gelecekte kullanılabilecek bir uygulama olarak, akıllı ev, bina veya şehir vb. uygulamalarında herhangi bir algılayıcı düğümün, ürettiği değerleri sosyal paylaşım sitelerine periyodik olarak iletebilecek ve bu bilgiler birçok kullanıcı ve uç sistem tarafından takip edilebilecektir. Akıllı ev, bina gibi uygulamalarla birlikte, akıllı tarım/orman sistemleri, ulaşım sistemleri de nesnelerin interneti dahilinde ortaya çıkan yeni uygulama alanlarını tanımlamaktadır (Taştan, 2019).

\section{1. İletişim Özellikleri}

IoT'nin çeşitli uygulamalarında kullanılan algılayıcı cihazlar IEEE 802.11, IEEE 802.15.4, IEEE ZigBee, IEEE Bluetooth, RFID gibi farklı haberleşme teknolojilerine sahiplerdir (Al-Sarawi, Anbar, Alieyan\&Alzubaidi, 2017). IoT haberleşme modelinde kablosuz algılayıcı cihazlar, İnternete bağlı bir ăg ara geçidine (gateway) bağlıdırlar. Ağ ara geçidi, düğümlerden belirli aralıklarla veri sorgulamakta veya düğümlere veri iletebilmektedir. Kablosuz cihazlarda üretilen veriler düşük veri iletimi kapasitesine $(\mathrm{kb} / \mathrm{s})$ sahip IEEE 802.15.4 veya benzer kablosuz bir teknoloji standardı ile iletilmektedir. IoT ortamının veri iletimi kapasitesini, algılayıc1 cihazların kaynak kısıtları (enerji, hesaplama gücü ve bellek) ve iletim ortamının güvensiz yapısı sınırlamaktadır. Kablosuz iletim ortamının kayıplı doğası ve ortamda yer alan cihazların kaynak kısıtları nedeniyle, haberleşme protokolleri mevcut internet protokollerinden farklı tasarlanmıştır (Akyildiz, Su, Sankarasubramaniam \&Cayirci, 2002). Bu nedenle, cihazların kısıtlı veri hızını ve güç kapasitesini göze alan aynı zamanda enerji tüketimini de minimize eden güvenilir iletişim protokolleri kullanılmaktadır.

IoT uygulamalarında yaygın olarak kullanılan kablosuz algılayıcı cihazlar, ad-hoc olarak çalışmakta ve veriyi tek sekmeli/çok sekmeli olarak uç düğüme bir ağ ara geçidi vasıtasıyla iletebilmektedirler. Kablosuz algılayıcı ağlarında 
kullanılan düğümlerin kısıtlı yaşam ömrü, saf dışı kalan düğümler nedeniyle ağ topolojisinin sıkça değişmesine sebep olmaktadır. $\mathrm{Bu}$ nedenle yönlendirme ve ortam erişim kontrolü iletişim katmanlarının tasarımı, topolojinin ölçeklenebilir ve ağ ömrünün uzun olması açısından kritik önem taşımaktadır.

\subsection{Cihaz Özellikleri}

IoT cihazları, donanım kaynakları bakımından yüksek ve düşük kapasiteli olarak sınıflandırılabilir. Bununla birlikte IoT cihazları denildiğinde genellikle düşük kapasiteli cihazlar akla gelmektedir. Bu cihazlar, işlemci gücü, depolama kapasitesi ve enerji kaynakları bakımından kısıtlı cihazlardır (Baccelli, Mehlis, Hahm, Schmidt\&Wählisch, 2014). Bu nedenle düğümlerde çalışan protokollerin bu kısıtları göz önüne alarak inşa edilmeleri gerekmektedir. Örneğin dügüümler haberleşme yaparlarken belirli zaman aralıklarında aktif ve uyku durumları arasında geçiş yaparak enerji tasarrufu yapmaktadırlar. Aktif durumda, radyo bileşeni ve işlemci bileşeni çalışmaktadır. Uyku durumunda ise bu bileşenlerin güç tüketimi minimize edilmektedir. Dügüümler, periyodik veya tetiklenme koşullarında bu iki durum arasında geçiş yapabilir (Akyildiz et al., 2002). Buna ek olarak düşük maliyetli aktif ve pasif RFID etiketleri akıllı ulaşım ve kimlik denetimi uygulamalarında elektronik barkod görevi görmesi nedeni ile cihazların/nesnelerin tanımlanmasında yaygın olarak kullanılmaktadır. Pasif RFID etiketleri, herhangi bir güç kaynağına sahip değildir ve kart okuyucu olmadan veri iletimi yapamamaktadır. Genellikle bu teknoloji, ticaret ve tedarik zinciri yönetimi uygulamalarında kullanılmaktadır. Bunun yanında güç kaynağına sahip aktif RFID etiketleri kargo takip vb. uygulamalarında elektronik barkod olarak kullanılmaktadır (Cho, Shim, Kwon, Choi, \& Kim, 2007).

\section{Nesnelerin Internetinde Kisitlar ve Çözüm Önerileri}

IoT kapsamında, söz konusu iletişim altyapısına dahil olan cihazların, servislerin ve iletilen verinin farklı yapıya sahip olması, ağ mimarisinde, ölçeklenebilirlik, enerji tüketimi, anlamsal uyumluluk, güvenlik gibi çözülmesi gereken problemleri ortaya çıkarmıştır (Atzori et al., 2010), (Derhamy, Eliasson\&Delsing, 2017), (Tourani, Misra, Mick, \&Panwar, 2018). Bu problemler, literatürde uygulama ve ağ katmanında uyumluluk yaklaşımları ile çözülmeye çalışılmıştır. Aşağıda önerilen çözüm yöntemleri incelenmiştir.

\subsection{Uygulama Katmanında Uyumluluk Problemi}

Uygulama katmanı ağ ara geçitleri, farklı bir uygulama protokolü ile cihazdan uygulama verisini elde ederek, kullanıcıya bilgi sağlamaktadır. Böylece cihaz ve son kullanıcı arasında yer alan ağ ara geçidi, bir vekil (Proxy) görevi görmektedir. $\mathrm{Bu}$ yöntemde, ağ ara geçitleri farklı her uygulama için protokoller arası anlamsal ve birebir çeviri yapmaktadır. Böylece farklı uygulama protokollerini kullanan cihazlardan, kullanıcıya veri aktarımı mümkün hale gelmektedir. Fakat protokoller arası anlamsal ve birebir çeviri yapılması karmaşık bir işlemdir ve diğer ă̆ ara geçidi çözümleri gibi merkezi kontrol gerektirmesi sebebiyle SPoF (Single Point of Failure) zafiyetleri vardır. Ayrıca protokoller arası birebir çeviri yapılması servis kalitesinin (QoS) düşmesine ve bant genişliğinin fazladan kullanımına sebep olmaktadır.
Şekil 2. A ̆g katmanı uyumluluk protokolleri

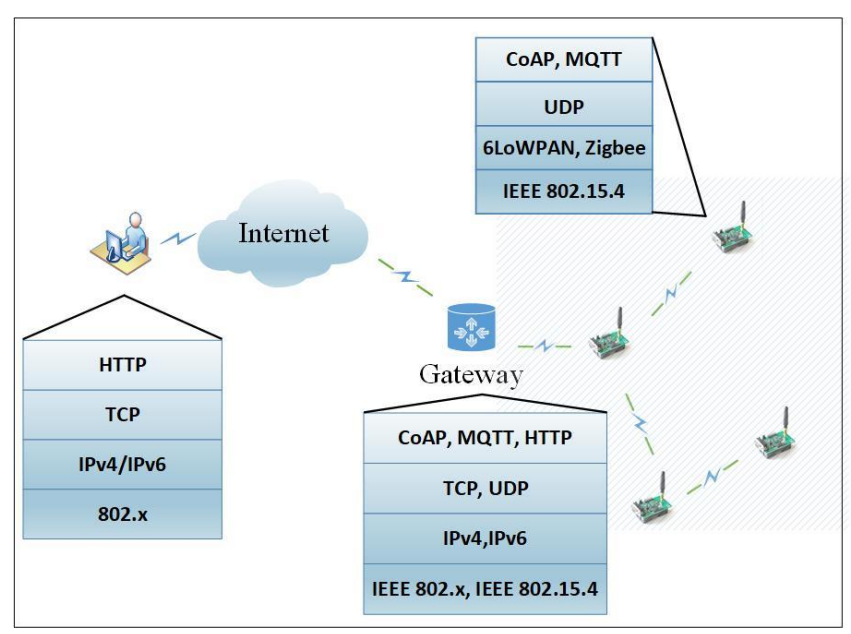

Bir diğer çözüm önerisi, aracı yazılımların (Middleware) kullanılmasıdır. Bu yöntemde IoT cihazlarından alınan verinin çeşitli uygulama protokollerinde kullanılabilmesi için servis modelleri geliştirilmektedir (Bromberg, \&Issarny, 2005), (Bromberg, Grace, \&Réveillère, 2011). Uygulama katmanı uyumluluk problemi üzerine SOA (Service Oriented Architecture) tabanlı çoklu bir protokol çeviricisi önerilmiştir (Derhamy et al., 2017). Çalışmada HTTP ve CoAP protokolleri arasında çeviri yapılmış, performansı ve gecikme süresi vekil protokol yöntemi ile kıyaslanmıştır. Deney sonuçları aracı yazılımların vekil protokol yöntemine kıyasla daha etkin bir çözüm olduğunu göstermiştir.

\section{2. Ăg Katmanında Uyumluluk Problemi}

IoT cihazlarının kullandı ̆̆ protokol yığını ve internet protokolleri arasındaki uyumluluk probleminin en güçlü çözüm önerisi açı standartlara dayalı IPv6 adresleme yöntemidir (Shelby et al., 2009). Internet Engineering Task Force (IETF) çalışma grubu IPv6 adresleme yönteminin kablosuz algılayıcı cihazlarda kullanılması üzerine standartlaşma çalışmalarını tamamlamıştır (Montenegro, Kushalnagar, Hui\&Culler, 2007). Böylece IPv6 paketlerinin 6LoWPAN, (Düşük güç - Kişisel Alan Ağları) ve 802.15.4 iletişim standardını kullanan düşük güç - kablosuz algilayic1 cihazlar (LLN - Low Power Lossy Networks) tarafindan kullanılması sağlanmıştır (Moritz, \&Golatowski, 2017). Böylece 6LoWPAN düğümlerinin internet ağ katmanı protokolleri ile uyumlu çalışması problemi çözülmüştür. Ancak, önerilen çözümler, uçtan uca bağlantının kurulmasını gerektiren bağlantı merkezli yaklaşıma sahip çözümlerdir. Ayrıca IoT cihazlarının enerji kısıtları göz önünde bulundurulduğunda, s1k veri iletişimi, veriyi sağlayan düğümlerin hareketli olması ve IP adresi çözümleme gereksinimi IoT uygulamalarının ölçeklenebilir olmasını zorlaştırmaktadır. Literatürde ă̆ katmanı uyumluluk çözümü için önerilen ă̆ mimarisinde kullanılan protokoller, örnek bir senaryo üzerinde Şekil 2' de gösterilmiştir. Bu mimaride, ağ ara geçidi protokoller arası çevirim yapmaktadır. HTTP protokolü kullanan uç cihaz, CoAP protokolü kullanan algılayıcı cihaz ile ağ ara geçidi ile haberleşmektedir.

\section{Bilgi Merkezli Ağlar}

Son yıllarda algılayıcı cihaz, akıllı telefonlar, sürücüsüz arabalar, veri merkezleri gibi milyonlarca cihaz internete bağlanabilmekte ve bu sayının geçen yıllarla birlikte üstel olarak artacağ1 öngörülmektedir. $\mathrm{Bu}$ cihazların mevcut Internet 
altyapısına dahil olması ile web ve video trafiğinde oldukça büyük bir artış görülmektedir. Günümüzde yaygın olarak kullanılan TCP/IP protokol yığını Internet modeli, istemci ve sunucu arasında adres tabanlı uçtan uca iletişimi desteklemektedir. Bununla birlikte mevcut gelişmeler uçtan uca bağlantıdan ziyade paylaşılan bilgiyi önemli hale getirmiştir (Waltari et al., 2016), (Babayiğit \& Doğan, 2019). Bilgi merkezli ağlar (Information Centric Networks- ICN), günümüzde kullanılan sunucu merkezli TCP/IP protokol yığınına alternatif olarak geleceğin internet modeli olarak önerilmiştir (Jacobson et al., 2009). Geleneksel TCP/IP modelinin temel aldı ̆̆ 1 ağ adresleme yerini ICN'de içerik/verinin adreslemesi olarak değiştirmektedir. Literatürde DONA (Koponen, Chawla, Chun, Ermolinskiy, Kim, Shenker\&Stoica, 2007), NetInf (Dannewitz, Kutscher, Ohlman, Farrell, Ahlgren\& Karl, 2013), NDN (Jacobson, et al., 2009), CCN (Severance, 2013) COMET (García et al., 2011), PURSUIT (Fotiou et al., 2012), CONET (Detti, Melazzi, Salsano, \&Pomposini, 2011), Green ICN (Tagami et al., 2016), MobilityFirst (Li, Zhang, Raychaudhuri, \&Ravindran, 2014) çalışmaları ICN ağ mimarisinin çeşitli kullanım senaryoları kapsamında tanımlanan farklı mimari önerileri olarak yerlerini almaktadır. $\mathrm{Bu}$ mimarilerin ortak önerisi, verinin adreslenebilmesi ile içeriğin üretildiği kaynak düğüme alternatif aynı veriye sahip farklı bir sunucudan temin edilebilmesidir. Veriyi, üreten "yayıncı" (publisher), ve talep eden, "abone" (subscriber) arasında uçtan uca bağlantı kurulması zorunluluğu ortadan kalkmıştır. Böylece belirli bir veriye ulaşmak için verinin benzersiz ismini bilmek yeterli olmaktadır ve buna ek olarak verinin isimlendirilmesi, farklı cihazlar tarafından önbellekte tutulmasını kolaylaştırmakta, verinin erişilebilirliğini arttırmaktadır. Veri sadece kaynak düğümden değil, aynı veriye sahip farklı yayıncılardan da ilgili abonelere de dağitılabilmekte ve bu sayede uçtan uca iletişimin neden olduğu internet trafiği azaltılmaktadır.

\section{Şekil 3. Bilgi merkezli ă̆ mimarisi NDN kullanım senaryosu}

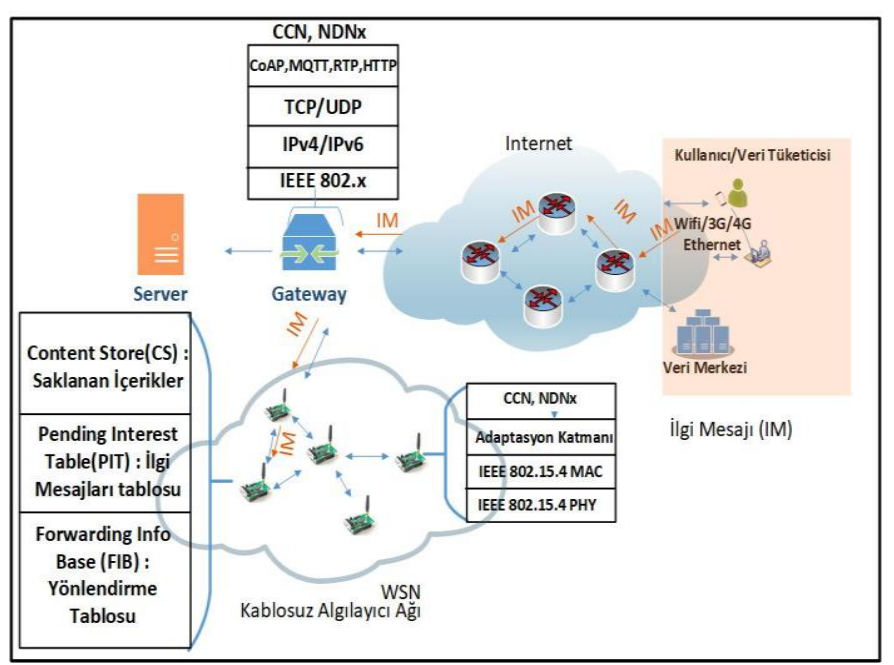

Bilgi merkezli ağları geleneksel ağlardan ayıran bir diğer özellik iletişimin verinin alıcısı tarafından başlatılmasıdır. Alıcı veya "tüketici" tarafından sorgulanan veri, veriyi içeren en yakın düğümden temin edilmekte ve verinin bulunması için gerekli sorgu ağ içerisinde yapılmaktadır. Verinin bulunduğu kaynaktan alıcıya ters yol izleyerek iletilmesi için kullanılan yönlendirme bilgisi sorguya eklenmekte veya yapılan sorguyu duyan herhangi bir düğüm tarafından veri kullanıcıya iletilmektedir. Bu iletim son kullanıcı tarafından başlatılır. Şekil 3' de bilgi merkezli ă̆ önerisinin bir uygulaması olan $\mathrm{CCN}$ ve NDN mimarisi için örnek bir kullanım senaryosu verilmiştir. $\mathrm{Bu}$ mimaride Veri (Data) ve İlgi (İnterest) paket yapıları kullanılmaktadır. Son kullanıcıya gönderilen veri (Data) paketi, iletişim yolu boyunca diğer cihazların içerik ön belleğinde (CS-Content Store) kaydedilir. Yol boyunca alınan veri paketlerinin iletim bilgisi, ayrıca ara düğümlerin yönlendirme tablosuna (FIB-Forwarding Information Base) kaydedilmektedir. Kullanıcıların istenilen veri için yaptıkları sorguya veri paketini ön belleğinde (CS) bulunduran en yakın dügüum cevap verir. $\mathrm{Bu}$ düğüm içerik ön belleği (CS-Content Store) tablosunda bulunan güncel veriyi kaynağa erişmeksizin iletebilmektedir. Sorgulanan veri düğümün CS' inde mevcut değilse sorgu, İlgi Mesajları Tablosuna (PITPending Interest Table) kaydedilir. Böylece aynı veri için farklı alıcılar tarafından gönderilen istek sorguları, önceden belirlenen zaman aşımı parametresine (Data Freshness) bağlı olarak diğer düğümler tarafından üretici kaynak düğüme yönlendirilmektedir. Zaman aşımı parametresi verinin güncelliğini sağlamak için kullanılan bir parametredir. Veri aşıma uğramadığı takdirde, ağ üzerinde veriyi önbelleğinde bulunduran herhangi bir sunucu bu istek mesajına yanıt verebilirken, güncel veriye sahip olmayan her düğüm eski veriyi CS' den silerek, sorguyu kaynağa doğru iletebilmektedir (Amadeo, Campolo, Iera\&Molinaro, 2015).

Günümüzde İçerik Dağıtım Ağlarında da kullanılan bilgi merkezli ağ paradigması web/video trafiği taşınan ağlar için önerilmiştir. Ancak, IoT cihazları, düşük işlemci gücüne sahip, enerjisi batarya ömrü ile kaynakları kısıtlı kablosuz algılayıcı ağ bileşenleridir. $\mathrm{Bu}$ nedenle, bu paradigmanın uygulandığı uç düğümler nesnelerin interneti cihazlarından işlemci gücü, hafıza ve enerji bakımından üstün olmaktadır. Bunun sonucunda bilgi merkezli ă̆ mimarisi, IoT cihazlarının kısıtları göz önünde bulundurularak yeniden tasarlanmaktadır (Baccelli et al., 2014).

\section{Bilgi Merkezli A $\breve{g}$ Mimarisinin Avantajları}

Bilgi merkezli ağ önerisinin, uçtan uca iletişimin yerini alarak geleceğin internetini tanımlaması beklenmektedir (Arshad, Azam, Rehmani \& Loo, 2018b). Günümüzde web/video trafiğindeki gecikmeleri azaltmak için tasarlanan içerik dağıtım sistemleri, bilgi merkezli ağ önerisinde tanımlanan yöntemleri uygulama katmanında kullanmaktadır. İçerik isimlerinin benzersiz olarak belirlenmesi ve içeriğin bulunduğu konuma ek olarak, daha önce iletildiği yol boyunca ara düğümler tarafindan önbellekte tutulması ağ trafiğini azaltmayı amaçlamaktadır. Buna ek olarak bilgi merkezli ağ önerisinde kullanılan mobilite yönetimi, IoT cihazlarında ağ katmanında da kullanılabilmektedir. Hareketli düğümlerin bağlantı durumunda ve topolojide sık değişikliklere neden olması IP iletişiminde karmaşık çözümler gerektirmektedir. ICN mimarisinde mobilite sebebi ile cevaplanmamış içerik İlgi Mesajları (IM) içeriği CS tablosunda bulunduran herhangi bir düğümden elde edilebilir. Böylece mobilite durumunda içerik temini IP iletişiminden daha hızlı ve güvenilir olmaktadır (Shang, Yu, Droms\&Zhang, 2016). Bilgi merkezli ağ mimarisinin uçta uca ağ mimarisinden farklı olarak önerdiği yöntemler aşağıda incelenmiştir.

\section{1. Üretilen İçeriğin ve Servislerin İsimlendirilmesi}

IoT uygulamalarının çoğunluğunda kullanıcılar, verinin hangi düğümden elde edildiğine kıyasla verinin kendisi ile 
ilgilenmektedirler (Waltari et al., 2016). Örneğin, trafik durumunu ögrenmek için yapılan bir sorgunun cevaplanması, hangi düğümün bu sorguya cevap verdiğinden daha önemlidir. Verinin ve kullanılan servislerin isimlendirilmesi, cihazların isimlendirilmesine kıyasla daha ön planda olmaktadır (Jacobson et al., 2009). Bilgi merkezli mimari, üretilen verinin benzersiz ve kalıcı olarak isimlendirilmesini amaçlamaktadır. Bu kapsamda, literatürde Hiyerarşik (Hierarchical), Düz (Flat Self-CertifyingBased), Özellik-Değer (Attribute-Based) ve Hibrit İsimlendirme (Hybrid Naming) olarak 4 farklı yöntem önerilmiştir (Arshad et al., 2018b). Bu yöntemler ICN mimarisinin kullanıldığ uygulamaların ihtiyaçları doğrultusunda geliştirilmiştir.

IoT uygulamaları için geliştirilmekte olan $\mathrm{CCN}$ ve NDN mimarileri, hiyerarşik isimlendirme (Hierarchical Naming) yöntemini kullanmaktadır (Arshad et al., 2018a). Bu yöntem tekdüzen kaynak tanımlayıcısı (URI - Uniform Resource Identifier) ile uygulama ve servisleri tanımlayan içerikleri isimlendirmektedir. Buna ek olarak, NetInf, DONA, MobilityFirst ICN mimarilerinde kriptografik hash algoritmaları ile sabit uzunlukta (Flat Naming) benzersiz içerik isimleri üretilmektedir (Baugher, Davie, Narayanan\& Oran, 2012). Green ICN mimarisinde içerik ve cihazlar, sahip olduğu özellikler temelinde (İçeriğin oluşturulma tarihi, türü, versiyonu vb.) isimlendirilmektedir (Attribute -Value based Naming) (Ascigil, Reñé, Xylomenos, Psaras, \&Pavlou, 2017).

\section{2. İçeriğin Önbelleğe Kaydedilmesi}

IoT cihazlarının donanımsal kısıtları göz önünde bulundurulduğunda, verinin iletildiği yol boyunca önbelleğe alınması, aynı iletişim kanalını kullanan, enerji kaynakları sınırlı cihazlar için fayda sağlamaktadır (Zhang, Li\& Lin, 2013). Verinin ağ içerisinde önbelleğe alınması yöntemi ile aynı verinin farklı istemciler tarafindan sik sorgulanması durumunda, ağ trafiğinin artması engellenerek bant genişliği ve enerji kullanımının azaltılması amaçlamaktadır. Buna ek olarak, verinin ara düğümlerde ön belleğe alınarak ağ içerisinde yayılması veriye erişim süresini azaltmaktadır. ICN mimarilerinin tümünde verinin önbellekte kaydedilmesi yöntemi kullanılmaktadır. Bu mimarilerin tasarım amaçları ve detayları doğrultusunda farklı mekanizmalar literatürde önerilmiştir. Bu mekanizmalar homojen (homogeneous), heterojen (heterogeneous), işbirlikli (cooperative), işbirliksiz (noncooperative), yol üzerinde (on-path) ve yol dişında (off-path) önbelleğe alma yöntemleri olarak sınıflandırılmıştır (Zhang, Luo\& Zhang2015).

Homojen ön belleğe alma mekanizmasında ağ içerisinde tüm yönlendiriciler aynı miktarda depolama kapasitesine sahiptirler ve içerikleri aynı kriterlere bağlı olarak kaydederler. Heterojen ön bellek mekanizmasında ağdaki her cihaz farklı depolama kapasitesine sahiptir ve buna bağlı olarak içerikleri kaydetmek için her düğüm kendi donanım özellikleri doğrultusunda yöntemler kullanabilir. İşbirlikli önbelleğe alma yönteminde, yönlendiricilerin içerik tablolarındaki kayıtlar yayınlanır ve içerik kaydetme kriteri buna bağlı olarak belirlenir. (Örneğin, bir sekme uzaklıktaki düğümün önbelleğinde yer alan veri, bu veriyi yönlendiren düğümün önbelleğine alınmayacaktır). İşbirliksiz önbelleğe alma yönteminde ise yönlendiriciler, içerik kayıtlarını yayınlamazlar ve yönlendirdikleri içerikleri birbirinden bağımsız olarak kaydederler. Yol üzerinde önbelleğe alma mekanizması, içeriklerin yönlendirildikleri tüm ara düğümler tarafından kaydedilmesidir. NDN, CONVERGENCE mimarileri bu yöntemi kullanmaktadır.

Yol dişında önbelleğe alma yönteminde ise içerikler yönlendirildikleri tüm ara düğümler tarafından kaydedilmezler. Bunun yerine içeriklerin kaydedileceği ara düğümler merkezi bir düğüm tarafindan belirlenir (Koponen et al., 2007). Bu mekanizma yönlendirme sistemi tarafından sağlanmaktadır ve DONA, MobilityFirst gibi merkezi isim çözümleme sistemine dayalı mimarilerde kullanılmaktadır. Aynı veri paketinin birden fazla yönlendiricide önbelleğe alınması, yönlendiricilerin içerik önbelleğinde (CS - Content Store) saklama alanının dolmasına neden olmaktadır. Bu durumda, içerik yönlendiricisi, çeşitli önbellek değiştirme algoritmalarını kullanarak, depoladığg veri paketlerini çıkarabilir (Podlipnig, \&Böszörmenyi, 2003), (Psaras et al., 2011). Bu algoritmalar, içeriklerin talep sayısına veya belirli bir süre aralığında talep edilme sıklığına bağlı olarak tasarlanmıştır (Bianchi, Detti, Caponi\&Melazzi, 2013), (Wang, Bi\&Wu, 2013), (Katsaros, Xylomenos\&Polyzos, 2011), (Katsaros et al., 2010).

\section{3. İçeriği Yayınlayan ve Kullanan Kaynakların Birbirinden Ayrılması}

IoT cihazları ağ içerisinde hareketli ve durağan olabilmektedir. Bu nedenle cihazlar arası bağlantı durumu ve ağ topolojisinde sık değişiklikler meydana gelmektedir. Geleneksel ağ mimarisinde, düğümlerin hareketli olması nedeniyle oluşan anlık topoloji değişiklikleri, iki cihaz arasında bağlantının kurulması ve sürdürülmesi için, iletişim protokolüne ek mesajlaşma yükü getirmektedir (Lin, Yu, Zhang, Yang, Zhang\&Zhao, 2017). Bilgi merkezli yaklaşımda spesifik bir veri, farklı düğümler tarafından önbelleğe alınır ve veriyi isteyen diğer düğümlere kaynaktan bağımsız olarak dağıtılır. Verinin, herhangi bir düğümden kalıcı bir bağlantı olmaksızın elde edilebilmesi, bağlantının korunmasını gerektirmemektedir. Böylece veriyi yayınlayan ve tüketen kaynaklar birbirinden ayrılır. Veriyi talep eden düğümün hareketli olması veya verinin üretildiği düğümün periyodik-bazlı çalışması nedeniyle erişilememesi durumunda veri, başka bir yönlendirici düğümden elde edilebilmektedir (Rao, Schelén, \&Lindgren, 2016). Bunun sonucunda birçok servis ve uygulama için veriye erişim imkânı artmaktadır (Lindgren, Abdesslem, Ahlgren, Schelén\& Malik, 2016).

\section{Kablosuz Algılayıcı Ağlarda Bilgi Merkezli Ă̆ Tasarımına Etki Eden Faktörler}

Bilgi merkezli ağ mimarisi kendine özgü tanımladığı özellikler (isimlendirme, önbellek ve güvenlik) ile günümüz internetine birçok fayda sağlama potansiyeline sahiptir (Ahlgren, Dannewitz, Imbrenda, Kutscher\&Ohlman, 2012). ICN temelli ölçeklenebilir bir IoT ağ mimarisi için, önerilen protokollerin ve teknolojilerin kablosuz algılayıcı cihazlarda tasarım faktörlerini göz önünde bulundurmasını gerektirmektedir (Lindgren et al., 2016). Bu durumlar 5 bölümde incelenmiştir.

\section{1. İsimlendirme Yöntemleri}

Nesnelerin interneti uygulamalarının çoğunluğunda veri ön plandadır (Severance, 2013). Ancak açma kapama komutu alabilen akıllı cihazlar gibi aktüatörlerin kullanıldığı uygulamalarda, cihazlara doğrudan komut gönderilmesine ihtiyaç duyulmaktadır (Amadeo, Campolo\&Molinaro, 2014). 
Ancak aktüatörlerin/cihazların isimlendirilmesi ICN mimarilerinde desteklenen bir özellik değildir. $\mathrm{Bu}$ nedenle aktüatörlerin işlevleri ile eşleşerek isimlendirilmesi yöntemi önerilmiştir (Amadeo et al., 2016). Örneğin, akıllı ev uygulamalarında, belirli bir aktüatöre erişmek ve durumunu değiştirmek için gönderilen mesaj "akilliev.tr/isik_sistemi/kat_2/cihaz/OFF" olabilir. Burada "akilliev.tr/isik_sistemi", uygulamanın ismini, "/kat_2/cihaz" aktüatörün ismini veya konumunu ve /OFF cihaza gönderilen işlevsel komutu belirtmektedir (Amadeo et al., 2015). Ayrıca, her bir cihazın benzersiz bir isme sahip olması gerekmektedir. Ancak cihazlara benzersiz olarak verilen isimler, bu cihazlara gönderilen komutların boyutundan daha büyük olmaktadır ve kısıtlı cihazlar için isim karşılaştırmalarının yapılmasında işlemci gücünün \%85 gibi büyük bir kısmını kullanmaktadır (Lindgren et al., 2016). Flat Naming isimlendirme yönteminde, cihazlar hash algoritmaları ile sabit uzunlukta olacak şekilde isimlendirilirler. Ancak bu yöntemde, cihazlara verilen isimler okunabilir değildir ve hiyerarşik isimlendirmede olduğu gibi parçalanma/birleşme (name aggreagation) özelliği olmaması nedeniyle ölçeklenebilir olmamaktadır.

ICN ağlarında, verinin isimlendirilmesi, verinin bulunması ve yönlendirilmesi amacı ile kullanılmaktadır. Literatürde, CCN ve NDN mimarilerinin kablosuz algılayıcı cihazlar için adaptasyon çalışmaları olan CCNx (Saadallah, Lahmadi\&Festor, 2012) CCN-lite (CCNLite, 2014) yazılımları mevcuttur. Bu yazılımlarda kullanılan hiyerarşik isimlendirme yöntemi isim ön eklerinin parçalanabilir/birleşir yapıda olması nedeniyle ölçeklenebilirdir. İsim çözümleme sisteminin yerine, istek mesajlarının yönlendirileceği ara yüzlerin bulunması için yapılan sorgu k1saltılabilir (Arshad et al., 2018a). ICN mimarilerinde hiyerarşik isimlendirmenin en çok kullanılan yöntem olmasının yanı sıra, içeriklere atanan isimlerin daha büyük boyuta sahip olması nedeni ile tek başına verimli bir çözüm olmamaktadır. Örneğin aktüatör veya algılayıcı isimleri, temsil ettikleri verilerden daha büyük olabilmektedir.

ICN ağları, verinin üretildiği kaynak ve uç düğüm arasında bağlantının kurulmadan iletilmesi yöntemi ile veriyi bir veya bir grup cihaz aracılığ isimlendirilmesine benzer olarak servislerin de benzersiz olarak isimlendirilmesi gerekmektedir (Lindgren et al., 2016). Servislerin isimlendirilmesi ile periyodik olarak sorgulanan bir veri, birçok düğüm tarafından takip edilmektedir. Servislerin, içerik temin etme, (content retrieval), içerik ismini girdi olarak alıp, karşılığında istenen içeriği gönderen veya bir aktüatöre verilen komutu girdi olarak alıp, aktüvatörlerden dönen durum kodunu göndermesi sağlanabilir (Amadeo et al., 2015).

\section{2. Önbellekleme Yöntemleri}

İçerik merkezli ağlarda performansı etkileyen en önemli faktörlerden biri verinin önbelleğe alınmasıdır. Aynı içeriğin farklı kaynaklardan sık temin edilmesi, sorgulanan içeriğin birçok ara düğümde önbelleğe alınmasını sağlar. İçeriklerin ağ içerisinde önbelleğe alınması, düşük güçte çalışan kablosuz algılayıcı cihazların görev döngüsü nedeniyle erişilemediği durumlara karşı toleransını arttırır ve gereksiz gönderimlerden kaçınılmasını sağlayarak enerji verimliliğini arttırma potansiyeline sahiptir (Lindgren et al., 2016). Ancak kablosuz algılayıcı cihazlarda depolama alanının sınırlı olması, önbelleğe alınabilecek veri miktarını kısıtlamaktadır.
ICN ağlarında önbellek isabet oranı (Cache Hit Ratio), önbellek isabet uzaklığı (Cache Hit Distance), işlem maliyeti (Operational Cost) vb. metrikler kullanılarak belirli içeriklerin önbelleğe alınması kararı verilmektedir. Önbellek isabeti, içeriğin bir kopyasını bulunduran ara düğümden talep edilmesidir. ICN mimarilerinde sorgulanan içeriğin kopyasını yönlendiren ara düğümler, sakladığı her içerik için isabet miktarı sayısını arttırmaktadırlar. Önbellek isabet uzaklığı, sorgulanan içeriği önbelleğinde bulunduran düğüm ile içeriği talep eden düğüm arasındaki uzaklıktır. İşlem maliyetini ise, içeriklerin ağ içerisinde yayınlanması sırasında oluşan ağ trafiğgi belirlemektedir. İçerikleri önbelleğine kaydeden düğümler, bu içeriklerin kendilerinde olduğunu ağ içerisinde yayınlamaktadırlar. $\mathrm{Bu}$ yayınlar, diğer düğümler tarafından yapılan sorguların yönlendirilmesini sağlamaktadırlar. Ancak önbellek kayıtlarında meydana gelen değişiklikler, ağ içerisinde birçok cihazın yönlendirme tablosundaki kayıtların değişmesine ve ek mesajlaşmalara neden olmaktadır (Zhang et al., 2015). Bu nedenle, önbelleğe alma yöntemlerinde, isabet oranı, isabet uzaklığı, işlem maliyeti metriklerinde bellek ve bant genişliği kullanımının optimize edilmesi ve kaynakların adil kullanılması (Wang, Tyson, Kangasharju\&Crowcroft, 2016) gerekmektedir.

Geleneksel ağlar için önerilen önbellek kayıt stratejileri, kablosuz algılayıcı cihazların kısıtları doğrultusunda geliştirilmelidir. Yol üzerinde önbelleğe alma mekanizması (onpath caching), iletim katmanında uçtan uca mesajlaşma sayısının azaltılması için kablosuz algılayıcı ağlarda çalışılmıştır (Hahm, Baccelli, Schmidt, Wählisch, Adjih\&Massoulié, 2017). Ancak bu yöntem her verinin sadece bir kez sorgulandığı durumlarda ağ performansına etki etmemektedir. $\mathrm{Bu}$ nedenle önbellek karar mekanizmalarının uygulama trafiğini sınıflandırması gerekmektedir (Nour et al., 2019). İşbirlikli önbelleğe alma mekanizması (Cooperative Caching) (Saha, Lukyanenko\&YläJääski, 2013) merkezi kontrol gerektirmesi nedeniyle oluşan ağ trafiğinin kısıtlı cihazların enerji tüketimine etkisini göz ardı etmektedir.

Kablosuz algılayıcı cihazlarda enerji tüketimini en aza indirgeyen ortak bir önbellek karar mekanizması düğümlerin uyku döngülerini en üst düzeye çıkararak tasarlanmıştır (Hahm et al., 2017). Bu çalışmada önbelleğe alınan içeriklerin ağ içerisinde yayılması stratejisi, kablosuz IoT sistemindeki içerik erişilebilirliğini arttırırken kaynakların korunabildiğini göstermektedir. Kaynakları kısıtlı IoT düğümlerinde, önbellek karar politikalarının, enerji, güvenlik ve gizlilik gereksinimlerini dikkate alarak optimize edilmesi önemli tasarım faktörleridir. Bununla birlikte, önbellek karar politikaları, algılayıcı cihazların ürettiği içeriklerin hızla değişebileceğini de göz önüne almalıdır. Ayrıca içerikleri uzun süreli kaydetmekten ziyade yayılma hızlarını iyileştirmeye odaklanması gerekmektedir (Amadeo et al., 2016).

Sınırlı depolama kapasitesine sahip kablosuz algılayıcı cihazlarda, içeriklerin önbelleğe alınması için çeşitli algoritmalar literatürde önerilmiştir (Nour et al., 2019): Her Yerde Önbelleğe alma (LCE - Leave Copy Everywhere) (huaRan, Lv, Zhang, yuanMa\&Xie, 2013), Olasılıklı Önbelleğe Alma (LCE-prob) (Zhang, Li\& Lin, 2013), İçerik Güncelliğine bağlı Önbelleğe Alma (Quevedo, Corujo\&Aguiar, 2014). Her yerde kopyalama (LCE) yöntemi, NDN mimarisinde kullanılmaktadır. LCE, içeriğin üretildiği ve sorgulandığı düğümler arasındaki tüm yönlendiricilerde önbelleğe alınmasını ve saklanmasını önerir. Ancak bu yöntem, aynı içeriğin birçok düğümde önbelleğe alınmasına neden olduğu için, ağ içerisinde saklanan içerik 
çeşitliliğini azaltır ve kısıtlı depolama alanının verimsiz kullanımına neden olur. LCE-prob, içerik çeşitliliğini arttırmak ve depolama alanının daha verimli kullanılması için önerilmiştir. Ara dügüumler $\mathrm{p}=1 /$ (sekme sayısı) olasılığı ile içerikleri önbelleğe alma kararını vermektedir. İçerik güncelliğine bağlı önbelleğe alma yönteminde ara düğümlerin önbellek kayıt tablosuna güncellik (Content Freshness) parametresi eklenmektedir. Ara düğümler, herhangi bir içerik talebini yanıtlamadan önce bu parametreyi kontrol etmektedir ve içeriği kaydetme kararını yine bu parametreyi kullanarak vermektedir. Güncellik eşiği, içeriği talep eden kullanıcılar tarafindan belirlenmektedir. İçeriklerin, belirli bir strateji ile önbelleğe kaydedilmesi, önbellek alanının verimli kullanılması açısından önemlidir. Ancak cihazların kısıtlı depolama alanına sahip olmaları, saklanan içeriklerin, içerikler tablosundan (CS) çıkarılmasını gerektirmektedir.

Önbellekte saklanan içeriklerin çıkarılması için LRU (Yakın zamanda erişim) veya LFU (En az erişim talebi) yöntemleri kullanılmaktadır. LRU yöntemi NDN mimarisinde kullanılmaktadır. LRU, en son erişilen içerikleri, saklama alanında öncelikli olarak tutmaktadır. Uzun süre talep edilmeyen içerikler saklama alanından çıkarılır. LFU yöntemi ise en az sıklıkta talep edilen içerikleri saklama alanından çıkarmaktadır. $\mathrm{Bu}$ yöntemlere ek olarak, önbelleğe alma yönteminin ă̆ performansına etkisini arttırmak için İçerik Popülaritesini kullanan saklama yöntemi önerilmiştir (Quevedo et al., 2014). $\mathrm{Bu}$ yöntem İçerik popülaritesi tablosu tanımlamaktadır. $\mathrm{Bu}$ tabloda önbellekte saklanan içeriklerin talep edilme sıklığ kaydedilmektedir. LRU ve LFU yöntemlerinden daha etkili olmasının yanında daha fazla işlemci gücü gerektirmesi nedeniyle kablosuz algılayıcı cihazlarda verimli bir yöntem olmamaktadır. İçeriklerin önbelleğe kaydedilmesinde kullanılan karar politikalarının ve önbellek içerik tablosundaki içeriklerin değiştirilmesi yöntemlerinin daha az bellek ve kaynak tüketimi ile veri çeşitliliğini arttırması amaçlanmalıdır.

\subsection{Servis Modelleri}

IoT uygulamalarında farklı tipteki algılayıcı düğümlerden verinin elde edilmesi için farklı servis modelleri kullanılabilmektedir. Literatürde başlica kullanılan servis modelleri Pull (Amadeo et al., 2015), Push (Amadeo et al., 2016), ve Publish/Subscribe (Fotiou et al., 2012) servis modelleridir. Aşağıda kullanılan bu servis modelleri ICN'de kullanılabilirliği açısından incelenmiştir.

\subsubsection{Pull Modeli}

Veriyi isteyen kullanıcı/uygulama bir Interest paketi gönderir. Interest paketi uç cihazdan istenen bir ölçüm değeri ya da bir aksiyon emri ile ilgili son durum olabilir. Böylece uç cihaz aksiyon sonucunu ya da istenen veriyi hazırlayıp Data paketi gönderir. Pull servis modelinde veri akışını başlatan verinin tüketicisidir bu nedenle bu servis modeli ICN mimarisinin temelinde desteklenmektedir.

\subsubsection{Push Modeli}

$\mathrm{Bu}$ servis modelinde, veri, ilgi paketi olmadan uç cihazdan kullanıcıya/uygulamaya gönderilir. Burada pull modelinden farkl1 olan durum, verinin herhangi bir interest paketi olmadan uç düğümden kullanıcıya gönderilmesidir. Belirli aralıklarla veya bir olayın gerçekleşmesine bağlı olarak veri, üretici kaynaktan tüketiciye iletilebilmektedir. Önerilen servis modeli bilgi merkezli ağlar tarafından desteklenmemektedir. Bu servis modelini bilgi merkezli ağlarda publish/subscribe modeli ile desteklemek mümkündür (Lindgren et al., 2016).

\subsubsection{Publish/Subscribe Modeli}

ICN ağlarında yayın/abone modeli desteklenmemektedir. Ancak bu model periyodik olarak içerik ilgi mesajlarının gönderilmesi ile taklit edilebilmektedir (Fotiou et al., 2012). Ancak abonelik sistemini taklit etmek için periyodik olarak gönderilen içerik ilgi paketlerinin, veri paketleri olduğu kadar çok sayıda ekstra ilgi mesajı paketi oluşturacağı göz önünde bulundurmalıdır.

\section{4. Üretilen İçeriklere Ait Özelliklerin Yayınlanması}

ICN'de düğümler, ürettikleri ve sakladıkları veriyi duyurmak için yayın yöntemini kullanmaktadırlar. Bu yayın sayesinde tüketiciler, içerik istek mesajlarını oluşturmaktadırlar. Ayrıca düğümlerin, kendilerine ait özellikleri duyurmasının yanı sıra, tüketicilere hangi verinin sağlanabileceğini keşfetmeleri için de bu yayın kullanılmaktadır. Çok sayıda yayıncının otomatik yayın ve keşif yapması ölçeklenebilirlik için kritik önem taşımaktadır. Yayıncı düğümler fonksiyonlarını duyurmalı ve istemcilere meta datayı (aktüatörler için girdi/çıktı bilgisi, parametreler, vb.) bildirmelidir. Ancak, düğüm özelliklerinin ve üretilen içeriğin duyurulması için kullanılan yayın yöntemi, kaynaklara bağlı belirlenmelidir. ICN ağlarında keşif yayını desteklenmektedir. Burada dinamik değişimler için gerçek zamanlı durum farkındalığı, veri yayılımı publish/subscribe veya push modeli ile sağlanabilir (Amadeo et al., 2016). Algılayıc1 cihazların, kablosuz ortam doğası sebebiyle diğer cihazlara ait verileri duyması keşif yayınlarını mümkün kılmaktadır. Ancak Ad-hoc ağlarda, önbellek kullanımı az miktarda mümkün gözükmesine rağmen kablosuz düğümler için strateji her zaman iletişimi minimumda tutarak, düğümlerin sadece kendi verileriyle işlem yapması olmalıdır (Baccelli et al., 2014).

\subsection{Güvenlik}

IoT sayesinde, verilerin çok sayıda kullanıcı ve uygulama tarafından erişilebilmesi, hemen hemen her ortam ile ilgili hassas bilgiler toplayan cihazların ve bu hassas bilgilerin güvenliğinin sağlanmasını daha önemli hale getirmiştir (Hassija, Chamola, Saxena, Jain, Goyal\&Sikdar, 2019). IoT kapsamında kullanılan kablosuz algılayıcı cihazların işlemci gücü, depolama alanı ve enerji kısıtları bu cihazların doğası gereği zafiyetli olmasına neden olmaktadır. Aynı zamanda kablosuz iletim ortamında hassas bilgileri içeren paketlerin kaybolması, bozulması gibi problemler bu ortamlarda sıklıkla tecrübe edilmektedir (Wang, Attebury\&Ramamurthy, 2006). Bu nedenle, IoT gibi karmaşık ve dinamik bir sistemde güvenliğin sağlanması kritik önem taşımaktadır. Bunun için, kablosuz algılayıcı ağların kullanıldığı uygulamalarda güvenlik gereksinimleri, Verinin gizliliği (Data Confidentiality), Kaynak Kimlik Doğrulaması (Source Authentication), Veri Bütünlügü (Data Integrity) ve Verinin Erişilebilirliği (Availability) olarak belirlenmiştir (Burhanuddin et al., 2018).

IP tabanlı İnternet uygulamalarında verinin kendisi ile entegre olan güvenlik modelleri desteklenmemektedir. Bunun yerine uçtan uca iletişimin kurulduğu ip ağlarında, güvenli oturumun oluşması için iki uç arasında iletişim kanalının güvenliği, TLS/DTLS/SSL güvenlik protokolleri ile sağlanmaktadır. Ayrıca içerik bütünlüğü ve kimlik doğrulaması gibi mekanizmalar üst katmanlara sonradan eklenmiştir. $\mathrm{Bu}$ 
protokollerin yüksek mesajlaşma gereksinimi, paketlerin gecikmesine sebep olarak ağ ve uygulama performansını düşürmektedir. Kısıtlı kaynaklara sahip kablosuz cihazların, güvenli bir iletişim kanalı sağlamak için harcamakta olduğu enerji, şifreleme algoritmaları için harcayacağ fazladır. Bu durumda, içeriğin kendisi ile entegre olan güvenlik yöntemleri kısıtlı cihazlar için verimli bir çözüm olma potansiyelini taşımaktadır (Rao et al., 2016). Bilgi merkezli ağ yaklaşımını, IoT uygulamaları ve geleceğin internet mimarisi için güçlü bir aday haline getiren mekanizmalardan biri de güvenliğin içeriğin kendisi ile sağlanmasıdır. ICN de verinin güvenliği, tamlık(integrity), doğruluk (authenticity), gizlilik (confidentiality/privacy) kontrolü ile sağlanmaktadır (Tourani, Misra, Mick\&Panwar, 2017). Tamlık kontrolü, isim - veri ikilisinden oluşmaktadır. Bu durumda verinin kendisine, verilen isimle erişilir. Verinin imza bazlı isimlendirme yöntemi ile erişilmesi doğruluk şartını da sağlamaktadır. Gizlilik kontrolü, iletim ve uygulama katmanlarında sağlanmaktadır. Bunun yanında, çeşitli IoT uygulamalarında cihazların güvenliği de sağlanmalıdır (Amadeo et al., 2016). Bu durumda kimlik denetimi ve yetkilendirme kontrolü gerekmektedir. Örneğin, bir aktüatöre komut gönderen cihazların kimlik denetiminden geçmesi gerekebilir. Ancak ICN, ilgi ve veri mesajlarının güvenliğine odaklanmaktadır. $\mathrm{Bu}$ nedenle kablosuz cihazları kullanan farklı servis modelleri için ek güvenlik mekanizmaları kullanılmalıdır.

Geleneksel ICN ağlarında, açık anahtarlı şifreleme (public key cryptography) yöntemi kullanılmakta ve veri/ilgi paketlerinin sonuna şifreleme bilgisi eklenmektedir. Kablosuz algılayıcı ağlarda, verinin gizliliği, anahtar paylaşımlı AES, Blowfish, Triple DES çeşitli şifreleme algoritmaları ile sağlanmaktadır (Panda, 2016). Ancak anahtar kullanımı ve şifreleme tek başına yeterli olmamaktadır. Kablosuz ortamda, şüpheli düğümler kolayca diğer düğümlerin iletişim kapsamına girerek hassas verileri gizlice dinleyebilmekte ve şifrelerini çözebilmektedirler (Roy\&Khan, 2019). Kaynak kimlik doğrulaması, veriyi gönderen ve alan düğümlerin, kötü amaçlı sahte paketlerle orijinal paketleri ayırt etmesi amaciyla kullanılmaktadır. Düğümlerin gizli anahtarları paylaşımı simetrik ve asimetrik şifreleme mekanizmalarıyla sağlanmaktadır (Shi, \&Perrig, 2004). Ancak kullanılan şifreleme mekanizmalarının, işlemci kullanımını ve iletişim paketlerinin boyutunu arttırması kaynakları kısıtlı kablosuz algılayıc1 cihazlarda verimliliği düşürmektedir (Tourani et al., 2018). Eliptik Eğri Şifreleme yöntemi diğer yöntemlere kıyasla daha küçük boyutta ürettiği anahtar yapısıyla güvenliği daha düşük işlemci gücü ile sağlamakta ve kısıtlı IoT cihazlarında uygulanabilmektedir. Ancak bu yöntem anahtar değişimi gerektirmektedir ve anahtarların uçlar arasında paylaşılması iletişime ek yük getirmektedir. Veri bütünlüğü, kablosuz iletim ortamının koşullarından kaynaklanan verilerin zarar görmesi veya kaybolmasının tespit edilmesi açısından önemlidir. Ancak kötü amaçlı düğümlerin yanlış veri enjekte etmesi veya iletişim paketlerinin içindeki verileri değiştirmesi söz konusu olabilir. Bu nedenle verinin bütünlüğü sadece hata kontrol mekanizmaları için değil, aynı zamanda güvenliğin sağlanması açısından da önemlidir. Verinin erişilebilir olması, kablosuz algılayıcı düğümler veya ağ içerisinde bir grup düğüm servis dışı bırakma (DoS - Denial of Service) saldırısına maruz kaldığında önemlidir. Literatürde her bir saldırı çeşidi için güvenlik mekanizmaları geliştirilmiştir. Saldırı bazlı güvenlik önlemi alan bu mekanizmalar uygulama gereksinimlerine özel olarak tasarlanmalıdır (Burhanuddin et al., 2018).

\section{Sonuç}

Nesnelerin interneti kavramı ile farklı kablosuz teknolojiye sahip çok sayıda heterojen cihaz internet altyapısında kendine yer bulmaktadır. $\mathrm{Bu}$ cihazların mevcut internet uygulama protokolleri ve birbirleri ile uyumlu çalışabilmesi problemi son yıllarda birçok araştırma grubunun ilgisini çekmiş ve farklı çözüm önerileri sunulmuştur. Açık standartlara dayalı 6LoWPAN teknolojisine sahip çözümler mevcut iletişim protokolleri ile ağ katmanında uyumlu çalışabilirliği ve kablosuz çok sayıda cihazın internete bağlanmasını sağlamıştır. Ancak bu çözümler, uçtan uca iletişimin kurulmasını ve sürdürülmesini gerektirmekte, İnternete bağlı cihaz sayısı ve üretilen verinin miktarı göz önünde bulundurulduğunda, uçta uca haberleşme modeli ölçeklenebilir olmamaktadır. Buna ek olarak IoT uygulamalarının çoğunluğunda kullanıcılar, hangi adresten elde edildiği bilgisi yerine verinin kendisi ile ilgilenmektedir. $\mathrm{Bu}$ noktada bilgi merkezli ağ mimarisi sahip olduğu farklı nitelikleri ile oldukça dikkat çekmiştir. Bu mimari, verinin isimlendirilmesi ile bulunduğu adresten bağımsız olarak iletilmesini, verinin ara düğümlerde önbelleğe alınması ile çok sayıda kullanıcının aynı veriyi elde etmek için üreteceği ağ trafiğinin düşürülmesini ve verinin kendi kendini sertifikalandırmasını sağlamaktadır. Bilgi merkezli ağ mimarisi kapsamında sunulan farklı çözümler ile IoT uygulamalarının ölçeklenebilirliğini artıracağ gözlemlenmektedir. $\mathrm{Bu}$ makalede gelecek nesil IoT uygulamaları için Bilgi merkezli A $\breve{g}$ mimarisinin kullanılabilirliği irdelenmiş ve halihazırda yapılan çalışmalar özetlenmiştir. Bilgi merkezli ağlar, IoT teknolojisinin yaygınlaşması ile daha da artacak olan Internet trafiği ve performans gereksinimi için ümit verici bir çözüm olarak literatürde yerini almaktadır. Bilgi merkezli ağların IoT uygulamalarında kullanılabilirliğini artırmak ve performans kriterlerini göz önüne alarak mevcut Internet ortamına entegrasyonunu temin etmek için önerilen yeni protokoller bu nokta da oldukça dikkat çeken bir konudur. Özellikle gittikçe artan trafik yükü, kullanıcı gereksinimleri, IoT cihazların kısıtları ve uygulamalarda kullanılan teknolojilerin heterojen yapılarını göze alarak geliştirilecek her çözüm yeni nesil İnternet çalışmalarında yerini almaya adaydır. Bu makale de kısıtlı donanımsal kaynaklara sahip IoT cihazlarının bilgi merkezli ă̆ mimarisini kullanabilmelerinde karşılaşılan mevcut problemler ve bu problemlere ait çözüm önerileri irdelenmiş, özellikle bu alanda çalışan uygulama tasarımcılarına ve ağ mühendislerine yardımcı olmak amaçlanmıştır.

\section{Kaynakça}

Ahlgren, B., Dannewitz, C., Imbrenda, C., Kutscher, D., \& Ohlman, B. (2012). A survey of information-centric networking. IEEE Communications Magazine, 50(7), 26-36.

Akyildiz, I., Su, W., Sankarasubramaniam, Y., \& Cayirci, E. (2002). Wireless sensor networks: a survey. Computer Networks, 38(4), 393-422. doi: 10.1016/s13891286(01)00302-4

Al-Sarawi, S., Anbar, M., Alieyan, K., \& Alzubaidi, M. (2017). Internet of Things (IoT) communication protocols: Review. 2017 8th International Conference on Information Technology (ICIT), 685-690. doi: 10.1109/icitech.2017.8079928

Amadeo, M., Campolo, C., \& Molinaro, A. (2014, December). Internet of things via named data networking: The support of push traffic. In 2014 International Conference and 
Workshop on the Network of the Future (NOF) (pp. 1-5). IEEE.

Amadeo, M., Campolo, C., Iera, A., \& Molinaro, A. (2015). Information Centric Networking in IoT scenarios: The case of a smart home. 2015 IEEE International Conference on Communications (ICC), 648-653. doi: 10.1109/icc.2015.7248395

Amadeo, M., Campolo, C., Quevedo, J., Corujo, D., Molinaro, A., Iera, A., ... \& Vasilakos, A. V. (2016). Informationcentric networking for the internet of things: challenges and opportunities. IEEE Network, 30(2), 92-100.

Arshad, S., Azam, M. A., Rehmani, M. H., \& Loo, J. (2018b). Recent advances in information-centric networking-based Internet of Things (ICN-IoT). IEEE Internet of Things Journal, 6(2), 2128-2158.

Arshad, S., Shahzaad, B., Azam, M. A., Loo, J., Ahmed, S. H., \& Aslam, S. (2018a). Hierarchical and flat-based hybrid naming scheme in content-centric networks of things. IEEE Internet of Things Journal, 5(2), 1070-1080.

Aschenbruck, N., \& Fuchs, C. (2011). STMP; Sensor data transmission and management protocol. 2011 IEEE 36th Conference on Local Computer Networks, 475-483. doi: 10.1109/lcn.2011.6115509

Ascigil, O., Reñé, S., Xylomenos, G., Psaras, I., \& Pavlou, G. (2017, September). A keyword-based ICN-IoT platform. In Proceedings of the 4th ACM Conference on InformationCentric Networking (pp. 22-28).

Atzori, L., Iera, A., \& Morabito, G. (2010). The Internet of Things: A survey. Computer Networks, 54(15), 2787-2805. doi: 10.1016/j.comnet.2010.05.010

Aydemir, F. (2019). Internet of Things Based Parking Lot LED Lighting System. European Journal of Science and Technology, (17), 71-76.

Babayiğit, B., \& Doğan, F. (2019) Bilgi Merkezli Ağların Mevcut Ağ Mimarisine Adapte Edilmesi. ISAS2019, Ankara, Turkey

Baccelli, E., Mehlis, C., Hahm, O., Schmidt, T. C., \& Wählisch, M. (2014). Information centric networking in the IoT. Proceedings of the 1 st International Conference on Information-Centric Networking - INC 14, 77-86. doi: $10.1145 / 2660129.2660144$

Baugher, M., Davie, B., Narayanan, A., \& Oran, D. (2012). Selfverifying names for read-only named data. 2012 Proceedings IEEE INFOCOM Workshops, 44(5), 12-19. doi: 10.1109/infcomw.2012.6193505

Bianchi, G., Detti, A., Caponi, A., \& Blefari Melazzi, N. (2013). Check before storing: What is the performance price of content integrity verification in LRU caching?. ACM SIGCOMM Computer Communication Review, 43(3), 5967.

Bormann, C., Castellani, A. P., \& Shelby, Z. (2012). CoAP: An Application Protocol for Billions of Tiny Internet Nodes. IEEE Internet Computing, 16(2), 62-67. doi: 10.1109/mic.2012.29

Bromberg, Y.-D., \& Issarny, V. (2005). INDISS: Interoperable Discovery System for Networked Services. Middleware 2005 Lecture Notes in Computer Science, 164-183. doi: 10.1007/11587552_9

Bromberg, Y.D., Grace, P., \& Réveillère, L. (2011). Starlink: Runtime Interoperability between Heterogeneous Middleware Protocols. 2011 31st International Conference on Distributed Computing Systems, 446-455. doi: 10.1109/icdes.2011.65
Burhanuddin, M. A., Mohammed, A. A. J., Ismail, R., Hameed, M. E., Kareem, A. N., \& Basiron, H. (2018). A review on security challenges and features in wireless sensor networks: IoT perspective. Journal of Telecommunication, Electronic and Computer Engineering (JTEC), 10(1-7), 17-21.

Castellani, A. P., Bui, N., Casari, P., Rossi, M., Shelby, Z., \& Zorzi, M. (2010). Architecture and protocols for the Internet of Things: A case study. 2010 8th IEEE International Conference on Pervasive Computing and Communications Workshops (PERCOM Workshops), 678-683. doi: 10.1109/percomw.2010.5470520

CCNLite (2014). Lightweight implementation of the content centric networking protocol.

Chen, E. T. (2017). The Internet of Things. The Internet of Things in the Modern Business Environment Advances in EBusiness Research, 167-187. doi: 10.4018/978-1-52252104-4.ch009

Cho, J., Shim, Y., Kwon, T., Choi, Y., \& Kim, S. (2007). SARIF: A novel framework for integrating wireless sensor and RFID networks. IEEE Wireless Communications, 14(6), 50-56. doi: 10.1109/mwc.2007.4407227

Cisco Annual Internet Report (2018-2023) White Paper. (2020, March 10). Retrieved from https://www.cisco.com/c/en/us/solutions/collateral/executive -perspectives/annual-internet-report/white-paper-c11741490.html

Dannewitz, C., Kutscher, D., Ohlman, B., Farrell, S., Ahlgren, B., \& Karl, H. (2013). Network of Information (NetInf) An information-centric networking architecture. Computer Communications, 36(7), 721-735. doi: 10.1016/j.comcom.2013.01.009

Derhamy, H., Eliasson, J., \& Delsing, J. (2017). IoT Interoperability-On-Demand and Low Latency Transparent Multiprotocol Translator. IEEE Internet of Things Journal, 4(5), 1754-1763. doi: 10.1109/jiot.2017.2697718

Detti, A., Melazzi, N. B., Salsano, S., \& Pomposini, M. (2011). Conet. Proceedings of the ACM SIGCOMM Workshop on Information-Centric Networking - ICN 11, 50-55. doi: $10.1145 / 2018584.2018598$

Dunkels, A., Alonso, J., \& Voigt, T. (2003). Making TCP/IP viable for wireless sensor networks.

Ersin, Ç. \& Öz, Ali. (2020). IoT Based Embedded System Desing and Implementation for Occupational Health and Safety. Avrupa Bilim ve Teknoloji Dergisi, (18), 494-504.

Fotiou, N., Nikander, P., Trossen, D., \& Polyzos, G. C. (2012). Developing Information Networking Further: From PSIRP to PURSUIT. Lecture Notes of the Institute for Computer Sciences, Social Informatics and Telecommunications Engineering Broadband Communications, Networks, and Systems, 1-13. doi: 10.1007/978-3-642-30376-0_1

G. García, A. Beben, F. J. Ramón, A. Maeso, I. Psaras, G. Pavlou, N. Wang, J. Śliwiński, S. Spirou, S. Soursos, \& E. Hadjioannou (2011). COMET: Content mediator architecture for content-aware networks. In 2011 Future Network Mobile Summit (pp. 1-8).

Gubbi, J., Buyya, R., Marusic, S., \& Palaniswami, M. (2013). Internet of Things (IoT): A vision, architectural elements, and future directions. Future Generation Computer Systems, 29(7), 1645-1660. doi: 10.1016/j.future.2013.01.010

Hahm, O., Baccelli, E., Schmidt, T. C., Wählisch, M., Adjih, C., \& Massoulié, L. (2017, September). Low-power internet of things with NDN \& cooperative caching. In Proceedings of 
the 4th ACM Conference on Information-Centric Networking (pp. 98-108).

Hassija, V., Chamola, V., Saxena, V., Jain, D., Goyal, P., \& Sikdar, B. (2019). A survey on IoT security: application areas, security threats, and solution architectures. IEEE Access, 7, 82721-82743.

hua Ran, J., Lv, N., Zhang, D., yuan Ma, Y., \& yong Xie, Z. (2013, August). On performance of cache policies in named data networking. In 2013 International Conference on Advanced Computer Science and Electronics Information (ICACSEI 2013). Atlantis Press.

Hunkeler, U., Truong, H. L., \& Stanford-Clark, A. (2008). MQTT-S; A publish/subscribe protocol for Wireless Sensor Networks. 2008 3rd International Conference on Communication Systems Software and Middleware and Workshops (COMSWARE 08), 791-798. doi: 10.1109/comswa.2008.4554519

Jacobson, V., Smetters, D. K., Thornton, J. D., Plass, M. F., Briggs, N. H., \& Braynard, R. L. (2009). Networking named content. Proceedings of the 5th International Conference on Emerging Networking Experiments and Technologies CoNEXT 09, 117-124. doi: 10.1145/1658939.1658941

Katsaros, K., Xylomenos, G. and Polyzos, G. (2010). A Hybrid Overlay Multicast and Caching Scheme for InformationCentric Networking. 2010 INFOCOM IEEE Conference on Computer Communications Workshops.

Katsaros, K., Xylomenos, G., \& Polyzos, G. C. (2011). MultiCache: An overlay architecture for information-centric networking. Computer Networks, 55(4), 936-947.

Koponen, T., Chawla, M., Chun, B.G., Ermolinskiy, A., Kim, K. H., Shenker, S., \& Stoica, I. (2007). A data-oriented (and beyond) network architecture. ACM SIGCOMM Computer Communication Review, 37(4), 181. doi: 10.1145/1282427.1282402

Li, S., Zhang, Y., Raychaudhuri, D., \& Ravindran, R. (2014). A comparative study of MobilityFirst and NDN based ICNIoT architectures. 10th International Conference on Heterogeneous Networking for Quality, Reliability, Security and Robustness, 158-163. doi: 10.1109/qshine.2014.6928680

Lin, J., Yu, W., Zhang, N., Yang, X., Zhang, H., \& Zhao, W. (2017). A Survey on Internet of Things: Architecture, Enabling Technologies, Security and Privacy, and Applications. IEEE Internet of Things Journal, 4(5), 11251142. doi: 10.1109/jiot.2017.2683200

Lin, J., Yu, W., Zhang, N., Yang, X., Zhang, H., \& Zhao, W. (2017). A survey on internet of things: Architecture, enabling technologies, security and privacy, and applications. IEEE Internet of Things Journal, 4(5), 11251142.

Lindgren, A., Abdesslem, F. B., Ahlgren, B., Schelén, O., \& Malik, A. M. (2016, January). Design choices for the IoT in information-centric networks. In 2016 13th IEEE Annual Consumer Communications \& Networking Conference (CCNC) (pp. 882-888). IEEE.

Montenegro, G., Kushalnagar, N., Hui, J., \& Culler, D. (2007). Transmission of IPv6 Packets over IEEE 802.15.4 Networks. doi: 10.17487/rfc4944

Moritz, G., \& Golatowski, F. (2017). IPv6 over Low-Power Wireless Personal Area Networks (6LoWPAN) and Constrained Application Protocol (CoAP). Industrial Communication Technology Handbook. doi: $10.1201 / \mathrm{b} 17365-40$
Nour, B., Sharif, K., Li, F., Biswas, S., Moungla, H., Guizani, M., \& Wang, Y. (2019). A survey of Internet of Things communication using ICN: A use case perspective. Computer Communications, 142-143, 95-123. doi: 10.1016/j.comcom.2019.05.010

Panda, M. (2016, October). Performance analysis of encryption algorithms for security. In 2016 International Conference on Signal Processing, Communication, Power and Embedded System (SCOPES) (pp. 278-284). IEEE.

Podlipnig, S., \& Böszörmenyi, L. (2003). A survey of web cache replacement strategies. ACM Computing Surveys (CSUR), 35(4), 374-398.

Psaras, I., Clegg, R. G., Landa, R., Chai, W. K., \& Pavlou, G. (2011, May). Modelling and evaluation of CCN-caching trees. In International Conference on Research in Networking (pp. 78-91). Springer, Berlin, Heidelberg.

Quevedo, J., Corujo, D., \& Aguiar, R. (2014, April). Consumer driven information freshness approach for content centric networking. In 2014 IEEE conference on computer communications workshops (INFOCOM WKSHPS) (pp. 482-487). IEEE.

Rao, A., Schelén, O., \& Lindgren, A. (2016, October). Performance implications for IoT over information centric networks. In Proceedings of the Eleventh ACM Workshop on Challenged Networks (pp. 57-62).

Roy, A. K., \& Khan, A. K. (2019). Architectural and Security Prospective of Wireless Mesh Network. International Journal of Computational Intelligence \& IoT, 2(1).

Saadallah, B., Lahmadi, A., \& Festor, O. (2012). CCNx for Contiki: implementation details.

Saha, S., Lukyanenko, A., \& Ylä-Jääski, A. (2013, April). Cooperative caching through routing control in informationcentric networks. In 2013 Proceedings IEEE INFOCOM (pp. 100-104). IEEE.

Sen, J. (2010). A survey on wireless sensor network security. arXiv preprint arXiv:1011.1529.

Severance, C. (2013). Van Jacobson: Content-Centric Networking. Computer, 46(1), 11-13. doi: 10.1109/mc.2013.34

Shang, W., Yu, Y., Droms, R., \& Zhang, L. (2016). Challenges in IoT networking via TCP/IP architecture. Technical Report NDN-0038. NDN Project.

Shelby, Z., \& Bormann, C. (2009). 6LoWPAN: the wireless embedded internet. Chichester, West Sussex, U.K.: John Wiley \& Sons.

Sheng, Z., Yang, S., Yu, Y., Vasilakos, A., Mccann, J., \& Leung, K. (2013). A survey on the ietf protocol suite for the internet of things: standards, challenges, and opportunities. IEEE Wireless Communications, 20(6), 91-98. doi: 10.1109/mwc.2013.6704479

Shi, E., \& Perrig, A. (2004). Designing secure sensor networks. IEEE Wireless Communications, 11(6), 38-43.

Stann, F., \& Heidemann, J. (2003, May). RMST: Reliable data transport in sensor networks. In Proceedings of the First IEEE International Workshop on Sensor Network Protocols and Applications, 2003. (pp. 102-112). IEEE.

Tagami, A., \& Arumaithurai, M. (2016). GreenICN Project: Architecture and Applications of Green Information Centric Networking. IEICE Transactions on Communications, E99.B(12), 2470-2476. doi: 10.1587/transcom.2016cni0001

Taştan, M. (2019). Nesnelerin İnterneti Tabanlı Akıllı Sulama ve Uzaktan İzleme Sistemi. Avrupa Bilim ve Teknoloji Dergisi, (15), 229-236. 
Tourani, R., Misra, S., Mick, T., \& Panwar, G. (2017). Security, privacy, and access control in information-centric networking: A survey. IEEE communications surveys \& tutorials, 20(1), 566-600.

Tourani, R., Misra, S., Mick, T., \& Panwar, G. (2018). Security, Privacy, and Access Control in Information-Centric Networking: A Survey. IEEE Communications Surveys \& Tutorials, 20(1), 566-600. doi: 10.1109/comst.2017.2749508

Waltari, O., \& Kangasharju, J. (2016). Content-Centric Networking in the Internet of Things. 2016 13th IEEE Annual Consumer Communications \& Networking Conference (CCNC), 73-78. doi: 10.1109/ccnc.2016.7444734

Wang, L., Tyson, G., Kangasharju, J., \& Crowcroft, J. (2016, November). FairCache: Introducing fairness to ICN caching. In 2016 IEEE 24th International Conference on Network Protocols (ICNP) (pp. 1-10). IEEE.

Wang, S., Bi, J., \& Wu, J. (2013). Collaborative caching based on hash-routing for information-centric networking. ACM SIGCOMM Computer Communication Review, 43(4), 535536.

Wang, Y., Attebury, G., \& Ramamurthy, B. (2006). A survey of security issues in wireless sensor networks.

Zhang, G., Li, Y., \& Lin, T. (2013). Caching in information centric networking: A survey. Computer Networks, 57(16), 3128-3141.

Zhang, G., Li, Y., \& Lin, T. (2013). Caching in information centric networking: A survey. Computer Networks, 57(16), 3128-3141.

Zhang, M., Luo, H., \& Zhang, H. (2015). A survey of caching mechanisms in information-centric networking. IEEE Communications Surveys \& Tutorials, 17(3), 1473-1499. 